our public acts to point always to the essence, and not to indicate the accidents. We, all of us, suffer from the complexity of modern life which presents masses of detail, demanding attention, and distracting our imaginations with what seems to be but " a multitude of single instances." We lose the thread of logic and law and only grasp the tangled skein of various issues. We are prone to class quickly a man, an action, a belief, and have done with it and him. It seems to save our time. In reality it dissipates and degrades our life. Let $\mathrm{u}:$ take a familiar example. We meet a man for the first time. Our friend classifies him for us. He is introduced to us as a man of affairs, a physician, or a lawyer. We accept the crude classification based on what he does, and we forget the divine possibilities of what he $i s$ or may be. We indolently accept a commercial classifica-

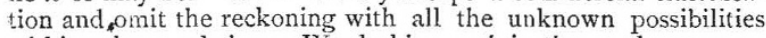
within a human being. We do him an injustice, and we go on to dull our own minds and sonls by repeated iterations of this stupid act until we become puppets meeting our like and not men meeting with our fellow-men. It is a lazy and a shiftless way, and unworthy of all of us. It inevitably dulls the mind by putting a word before a thought, a phrase before a principle, and this process ceaselessly repeated gradually eliminates all thought, and living men become mere dead automata in each other's eyes. Hardly any man is so dull that there are not possibilities unknown to you within him. To classify him at a glance and by a phrase is to deny the divine spark in him and a perceptive sense in your own heart. It is true that the higher a man's profession is the nearer should his life approach to the type signified by the name of that profession. It is safer to think you know mewhat of a poet when you hear that he is such than to predict the quality of a physician from his degree of doctor.

Complete Human Btings.-The University has no higher ideal than to train its students so that their practice may agree with their professions. But their complete professions are by no means signified by the formal degrees with which we invest them.

We grant the degree of A.B. to successful candidates. But A.B. does not really stand for what we have tried to teach. What we wish to teach our students and ourselves is to be complete human beings. Nothing less than this. There can be nothing more. We wish them to be H.B.'s first-human beings-and A.B.'s afterwards. Let any one of us try to see what is meant by a deserved title such as this. What is a human being con lete in every way? Is there a manly virtue, is there a ferninine grace, is there a divine aspiration which we can conceive to be lacking to such a personality? How carelessly we use the phrase, and with what debased significance! Is the man who has sacrificed his very nature to the service of money deserving of the title? Is it any better if power be the thing he has sold his birthright for? or vanity? or pleasure? or fame?

The moment we reflect upon the inner senses and upon the connoted meaning of the word, we see how we have debased it. We are used to lift a beggar from the ditch and to say with a pity that is half repulsion --at least he is a human being. Bu when we reflect we see that we can give no higher praise than this to the men who are the chiefest glories of the race. 'Think of David, King of Israel. How can we praise him, appreciate him, feel his power over us at this day, better than to recognise that he was a complete being human in every part? That is allied directly with Divinity. St. Peter, Socrates, the great Emperor Marcus Aurelius-these touch us through a chord of complete unison of their human natures with ours. What is it that is common to the great Alfred of England and to the poet who sang the beauties of the daisy overturned by the plough ? What but this human nature that embraces our own and harmonises with its every part?

In America, young as we are, we have had our complete human beings. We can point to the oration at Gettysberg and know that the man who wrote it did so out of the fulness of a complete human nature. The soldier whose forces were overcome on that fearful field will live in history by his martial deeds, but he will be cherished in our hearts for the rounded symmetry of his humanity. In fiction we have all given this high degree. Where can we find more perfect examples than Col. Newcome or Henry Esmond? Is it not worth reflection to see why it is that these stand for us as types of what a man can become ?

I think we can conceive of what our ideal of a human being should be by seeking to find the common quality of men so re- moved from each other in character and circumstance as King David, Peter the A postle, Socrates, Alfred, Burns, Lincoln, Lee. The great Marcus has even defined such a man for us in formal words: he is "a man who delays $n$ t to be among the best, like a priest and minister of the gods ; who uses the deity planted within him, which makes him uncontaminated by pleasure, unharmed by pain, untouched by insult, a fighter in the noblest fight, not overpowered by any passion, deep-dyed with justice, and accepting with his soul all that happens and is his portion."

It must be our aim and end to fix clearly in the mind of every pupil that the whole object of his college course should be one and the same as the whole object of his entire life, namely, to be a real human being. Not to strive for partial knowledge, for partial facts as an end, and finally to be graduated a Bachelor of Arts, but to strive for complete and utter manhood and to add to its magnificent qualities all the learning which our schools afford simply as a help towards carrying out his inmost and his highest aspirations. Each one of us should be ever striving to deserve among our fellows and in our most secret life this chief of all titles. The one that expresses the sum of all achievement possible to us; since when it is attained it fixes us as wholly human, and thus made in the image of divinity. The best title of our Master was the Son of Man, and $\mathrm{He}$ descended to this to show the term to which we might attain.

$A$ Word to the Graduates,-And now, members of the graduating class, I wish to say one parting word especially to you, who are soon to see the formal signs of the approval of your professors and of our governors--the Regents.

In the name of the University I welcome you to your new estate. If we have done our duty by you, you are equipped for the beginning of your maturer life. If you do your duty by yourselves and by society there is nothing which you need fear to undertake. Here, on the very borders of the most western sea, in a golden land of promise, let me repeat to you the noble words which were first written down eighteen hundred years ago, in the midst of a savage wilderness, in the presence of hostile barbarians, by the hand of the greatest and most virtuous of the rulers of imperial Rome, sitting alone and silent in his soldier's tent. Let these great sentences be at once our farewel and our God-speed to each one of you :-

"If thou workest at that which is before thee, following right, reason calmly, vigorously, allowing nothing to distract thee, but keeping thy divine part pure, although bound to give it back immediately-if thou holdest to this, expecting nothing and fearing nothing, with heroic truth in every word and sound which thou utterest, then thou wilt live happy-and there is no man able to prevent thee."

\section{ANTARCTIC EXPLORATION}

THE author began by referring to the results established by Gauss in 1839 . Gauss proved: "(I) That the knowledge of $\mathrm{Y}$ (the west component of the horizontal component of terrestrial magnetism, called usually $\mathrm{X}$ ) over the whole earth, along with the knowledge of $\mathrm{H}$ (the north component of $\mathrm{H}$ ) at all points on a line running from one pole to the other, is sufficient for the foundation of a comflete theory of the magnetism of the earth. (2) That a finally complete theory was also deducible from the simple knowledge of $Z$ (the component of the earth's magnetism, that is directed to the earth's centre) on the whole earth's surface." There existed, for a large part of the earth's surface, data for large charts of the normal values of the declination of $\mathrm{H}$ and of $\mathrm{Z}$, at the epoch 1880 , from which $\mathrm{X}, \mathrm{Y}$, and $Z$ could readily be deduced. These charts were accurate for the zone lying between $60^{\circ} \mathrm{N}$. and $50^{\circ} \mathrm{S}$. lat. (except for some parts of North Asia and of Central Africa); they were less accurate for $60^{\circ}$ to $70^{\circ} \mathrm{N}$. lat, and $50^{\circ}$ to $60^{\circ} \mathrm{S}$. Beyond these limits in the south, lay regions almost unvisited since Ross's Expedition in I840-43; so that the charts were correspondingly weak in those latitudes. The charts show that the Challenger crossed the Antarctic Circle about the meridian $79^{\circ} \mathrm{E}$. These and other somewhat recent observations made between $50^{\circ}$ and $60^{\circ} \mathrm{S}$. lat., show that considerable changes in the magnetic elements have occurred since Ross's time, and therefore the charts for 1880 cannot be com$x$ "On the Advantages to the Science of Terrestrial Magnetism to be obtained from an Expedition to the Region within the Antarctic Circle." Abstract of a paper read at the Birmingham meeting of the British Associa tion by Capt. Ettrick W. Creak, R. N., F.R.S. 
pleted, especially as our knowledge of the changes is too limited to permit of the use of Ross's observations. Further it is desirable to have actual verification of Gauss's extension by theory of the magnetic elements at places where they are known to places where they are unknown. The position of the south magnetic pole is still undetermined, and magnetic observations are wanted from $40^{\circ} \mathrm{S}$. to the geographical pole. For the carrying out of these views, Melbourne Observatory, being furnished with the necessary instruments, would serve admirably as a base station, with subsidiary bases at the Cape, and at Sandy Point, Magellan Strait, for the use of portable absolute instruments. Much of the survey could be done on board ship at sea, observations having now become so trustworthy by the process of "swing ing ship." Portable instruments could also be used on ice, where their readings would be specially free from sources of error. The great effect of the ship's iron in high latitudes can be got rid of by experience, as proved in the voyage of the Challenger, an important matter being a proper position on board far the instruments. This position could be chosen immediately after the selection of the ship. The error in the vertical component varies with the "heel" of the ship; the horizontal error can be eliminated by the process of "swinging."

\section{NOTES FROM THE OTAGO UNIVERSITY MUSEUM}

VIII. - On the Claspers of Callorhynchus

I N my friend Mr. Patrick Geddes' able article, "Reproduction," published in the recently issued twentieth volume of the "Encyclopæedia Britannica" (ninth edition), the following note occurs (p. 410) :-

"In the curious Holocephalous fish, Callorhynchus, Jeffery Parker has recently adduced arguments for regarding the claspers as the surviving rudiments of a third pair of limbs."

As this passage was written under the mistaken impression that a somewhat wild theory, hither only communicated privately to one or two friends, had been published, $\mathrm{I}$ think it will be advisable to state exactly the grounds on which I am disposed, provisionally, to consider the Holocephali as the only existing hexapodous vertebrates.

In the Elasmobranchii (Plagiostomi) the male is well known to possess a single pair of so-called claspers, each having the form of a plate rolled longitudinally upon itself so as to produce an incomplete tube, and supported by a more or less complicated cartilaginous skeleton continuous with the basipterygial cartilages of the pelvic fin.

In Callorkynchus, on the other hand-and I believe the same applies to Chimara, of which I have no specimen-the male has two pairs of organs, which may be called respectively the anterior and the posterior claspers. The posterior claspers are evidently homologous with the claspers of the Elasmobranchs : they occur in the same position, have the form of a plate rolled longitudinally into a tube, and are supported by a prolongation of the basipterygium. No doubt, like the corresponding organs in sharks and rays, they have an intromittent function.

The structures I call anterior claspers are situated a short distance cephalad of the vent, inclosed, in the position of repose, in a pouch of skin having a somewhat contracted slitlike aperture, so that the clasper is ordinarily hidden from view. The aperture of the sac is erronzously marked "peritoneal aperture" in Giinther's figure of Chimera colliei ("Study of Fishes," p. I84). In connection with the sac is a gland secreting a lubricating fluid, and closely resembling the well-known gland of the Elasmobranch clasper.

In the female, although the clasper itself is absent, a small glandular sac occurs in the corresponding position.

The anterior clasper itself is a somewhat complicated organ, consisting of three chief parts supported by cartilage. The largest of these, which forms the main support of the whole structure, is a strong irregular cartilaginous plate, articulated by an elongated surface with the anterior border of the pubic portion of the pelvic girdle in such a way that when in its ordinary position of retraction, the whole apparatus is folded back in the hollow furnished by the outer surface of the pubic cartilage. To this principal cartilage of the anterior clasper are attached two others : one a thin delicate plate, shaped like the human external ear, the use of which is not obvious; the other a somewhat thicker plate, rolled upon itself to form a tube, in much the same way as the posterior clasper, and evidently serving as a duct for the passage of the above-mentioned secretion. The whole apparatus is covered with soft mucous membrane, except the free portion of the prineipal cartilage which is studded with minute sharp denticles

The clasper is exserted by the action of a strong muscle arising from the inner face of the pubic cartilage and passing over its anterior border to be inserted into the principal cartilage of the clasper. The plane of movement of the organ is nearly horizontal.

That a serial homology (homoplasy) exists between the anterior and the posterior claspers is suggested by the following facts:(a) The general similarity of their structure; (b) they both articulate, mediately or immediately, with the pelvic cartilage (c) they both lie in the line of Balfour's lateral ridge, i.e. of the hypothetical lateral fin; $(d)$ the blood from both appears to be poured into a vein which is clearly the representative of the lateral vein of Elasmobranchii, which latter I have adduced reasons for considering as the vein of the proto-vertebrate lateral fin (Trans. N.Z.Inst., vol. xiii. p. 4I3, and vol. xv. p. 222; Proc. Roy. Soc., June I886).

I regret that all my efforts to obtain earlier embryos of Callorhynchus than those I described three years ago in NATURE (vol. xxix. p. 46) have failed. It must therefore remain for future investigations to decide whether the anterior clasper of Holocephali is developed from a portion of the lateral ridge which usually atrophies, and whether its skeleton is formed by the concrescence of pterygiophores (radial fin-cartilages).

At present, therefore, the hypothesis that the anterior claspers of the Holocephali represent a middle pair of limbs is nothing more than a deduction from an unproved theory. I should not have ventured to publish it without further evidence if my friend. had not, quite inadvertently, forced my hand.

Dunedin, N.Z., August I6 T. JeFFery PARKER

\section{SOCIETIES AND ACADEMIES SYDNEY}

Linnean Society of New South Wales, July 28.-Prof. W. J. Stephens, M.A., F.G.S., President, in the chair.-The following papers were read:- On some new or rare fishes from the Australian region, by E. P. Ramsay, F.R.S.E., and J. Douglas-Ogilby. A few notes are given on the curious Blennoid genus Xiphasia of Swainson, and a description is given of a species-Xiphasia setifer, Swainson-now for the first time taken in Australian waters. Arrhamphus sclerolepis and Gastrotokeus biaculeatus are recorded as fishes not previously seen on the New South Wales coast. - Catalogue of the Australian Coleoptera, part 5, by George Masters. The present part contains the large family of the Curculionidæ, numbering over I200 species, and bringing the total number now catalogued up to. 5625. It was stated that probably two more parts would complete the order Coleoptera.-Miscellanea Entomologica, No. 2 : the genus Liparetrus, by William Macleay, F.L.S. This is a complete monograph of the genus Liparetrus. All the old species are redescribed, many new ones added, and the genus is subdivided into several sections and sub-sections. Altogether about 100 species are characterised.-Revision of the Australian Lepidoptera, No. 1, by E. Meyrick, B.A., F.E.S. Five families of the Macro-Lepidoptera, or Lesiadæ, Arctiadæ, Hypsidæ, Syntomididæ, and Zygænidæ, are monographed, numbering about 150 species, about half that number being new to science. -Notes on synonymy of Australian Micro-Lepidoptera, by $\mathrm{E}$. Meyrick, B.A., F.E.S. The synonymy of fifteen species of Micro-Lepidoptera is corrected, from an examination of specimens in the British Museum.

\section{PARIS}

Academy of Sciences, October I8.-M. Jurien de la Gravière, President, in the chair.-A theory of the unequal flow of gases, by M. Haton de la Goupillière. Although geometricians have already solved a few questions relating to the unequal movement of fluids, no general theory appears to have yet been applied to the subject so far as regards the gases. The object of the present paper is to make good this want, and to present a complete solution of the problem in connection with the receptacles of compressed air for locomotives or tramways filled from reservoirs maintained by the compressing engines at a constant tension. - Researches on the tension of the dry bicarbonate of ammonia, by MM. Berthelot and André. The authors here discuss the important and complex problem, whether the tension of ammonia in the air, the ground, and natural waters, and its movements between these various n.ediums, is to be assimilated 